\title{
Bayes factor analysis for detection of time-dependent higher-order spike correlations
}

\author{
Hideaki Shimazaki*1, Shun-ichi Amari1 ${ }^{1}$ Emery N Brown²,3 and Sonja Grün ${ }^{1}$
}

\author{
Address: ${ }^{1}$ Theoretical Neuroscience Group, RIKEN Brain Science Institute, Wako-shi, Saitama, Japan, ${ }^{2}$ Anesthesia and Critical Care, Massachusetts \\ General Hospital, Boston, MA, USA and ${ }^{3}$ Harvard-MIT Division of Health Sciences and Technology, Cambridge, MA, USA \\ Email: Hideaki Shimazaki* - shimazaki@brain.riken.jp \\ * Corresponding author
}

from Eighteenth Annual Computational Neuroscience Meeting: CNS*2009

Berlin, Germany. 18-23 July 2009

Published: 13 July 2009

BMC Neuroscience 2009, I0(Suppl I):P99 doi:I0.I |86/I47|-2202-I0-SI-P99

This abstract is available from: http://www.biomedcentral.com/I47I-2202/I0/SI/P99

(c) 2009 Shimazaki et al; licensee BioMed Central Ltd.

Precise spike coordination in the spiking activities of a neuronal population is discussed as an indication of coordinated network activity in form of a cell assembly relevant for information processing. Supportive evidence was provided by the existence of excess spike synchrony occurring dynamically in relation to behavioral context [1-3]. These findings are based on the measured dependence of multiple neurons against the null-hypothesis of full independence. However, neurons jointly involved in assemblies may express higher-order correlations (HOCs) in their spiking activities [4]. By characterizing the spatiotemporal pattern of parallel spikes with the HOCs, one may elucidate assembly activities and possibly their behavioral relevance. To describe the HOCs in parallel spike trains, the log-linear model is an useful model because it provides a well-defined measure of correlation based on information geometry [5]. Former studies on HOCs performed a regression analysis on parallel spike trains using either a full log-linear model [6] or a log-linear model containing up to pairwise interaction only (maximum entropy model) [7]. The existing approaches, however, assume stationarity, a condition that is typically not fulfilled in neuronal spike data from awake behaving animals. Recently, we established a method for estimating the dynamics of HOCs by means of a state-space analysis [8] with a log-linear observation model to trace active assemblies [Abstracts in SAND4, NIPS08 Workshop, and Cosyne09, [9]]. However, presentation of the smoothed posterior estimates only may mislead neurophysiologists to presume the existence of the HOC at the moment when no or weak evidence is available. Furthermore, the method did not provide a statistic to detect an assembly in which cells are jointly connected through multiple correlations. In this contribution, we investigate the method of the Bayesian hypothesis testing to answer which compositions of parallel spikes exhibit the joint HOCs, and if they do, when those HOCs appear. We computed the Bayes factor [10] of temporally local spike observation to gain evidence of positive joint HOCs of a specific set of parallel spike sequences against negative HOCs by using filter and one-step prediction odds. The proposed method may be useful to detect the dynamic assembly activities, their composition and behavioral relevance when applied to simultaneous recordings of neuronal activity of behaving animal.

\section{Acknowledgements}

This work was supported in part by JSPS Research Fellowships for Young Scientists (HS), ROI MH59733/DPI OD 003646 (EB), and RIKEN Strategic Programs for R\&D (SG).

\section{References}

I. Vaadia E, Haalman I, Abeles M, Bergman H, Prut Y, Slovin H, Aertsen $A$ : Dynamics of neuronal interactions in monkey cortex in relation to behavioral events. Nature 1995, 373:515-518.

2. Riehle A, Grün S, Diesmann M, Aertsen A: Spike synchronization and rate modulation differentially involved in motor cortical function. Science 1997, 278:1950-1953. 
3. Fujisawa S, Amarasingham A, Harrison MT, Buzsáki G: Behaviordependent short-term assembly dynamics in the medial prefrontal cortex. Nat Neurosci 2008, I I:823-833.

4. Grün S, Abeles M, Diesmann M: Impact of higher-order correlations on coincidence distributions of massively parallel data. Lect Notes Comput Sci 2008, 5286:96-I I 4.

5. Amari S: Information geometry on hierarchy of probability distributions. IEEE Trans Inf Theory 200I, 47:I70I-I7II.

6. Martignon L, Hasseln HV, Grün S, Aertsen A, Palm G: Detecting higher-order interactions among the spiking events in a group of neurons. Biol Cybern 1995, 73:69-8I.

7. Schneidman E, Berry MJ, Segev R, Bialek W: Weak pairwise correlations imply strongly correlated network states in a neural population. Nature 2006, 440:1007-1012.

8. Smith AC, Brown EN: Estimating a state-space model from point process observations. Neural Comput 2003, 15:965-9919.

9. Shimazaki H, Amari S, Brown EN, Grün S: State-space analysis on time-varying correlations in parallel spike sequences. Proc IEEE ICASSP 2009.

10. Kass RE, Raftery AE: Bayes factors. J Am Stat Assoc 1995, 90:773-795

Publish with Bio Med Central and every scientist can read your work free of charge

"BioMed Central will be the most significant development for disseminating the results of biomedical research in our lifetime. "

Sir Paul Nurse, Cancer Research UK

Your research papers will be:

- available free of charge to the entire biomedical community

- peer reviewed and published immediately upon acceptance

- cited in PubMed and archived on PubMed Central

- yours - you keep the copyright 